\title{
The Training Strategy of Musical Appreciation in Piano Works
}

\author{
Wang Lei \\ ART Institute, Jiujiang University
}

Keywords: learning stage; piano works; music appreciation; ways to improve;

\begin{abstract}
In today's society, quality education in our country has previously developed, and people's ability to appreciate music has also gradually increased. Therefore, the ability to cultivate students' musical appreciation of piano work in the learning stage can effectively improve the students' aesthetic ability. They can learn music and experience music through music appreciation, and finally realize the melody changes, emotional changes, and rhythm changes in the appreciation of piano work. This paper firstly introduces the significance of cultivating piano music appreciation, and then expounds the problems in the music appreciation of piano work in the learning stage. At last, it puts forward ways to improve the piano works of music appreciating ability in the learning stage.
\end{abstract}

\section{Introduction}

Music appreciation is an activity to understand music, taste music, evaluate music, and appreciate music. It is equally a way to improve people's aesthetics. Therefore, cultivating modern students' music appreciation ability can effectively enhance students' cultural quality. Appreciation of piano work is an auditory art. The piano makes a very strong penetrating power and expressive power. It can imitate some natural sounds such as flowing water and birdsong, and more importantly, it can demonstrate people's thoughts and feelings. In the process of appreciation, we must include the ideological connotation of music and music. Therefore, we must appreciate the piano work and music knowledge as the starting point to appreciate the piano works, and we must also effectively combine them.

\section{Significance of Cultivating Musical Appreciation in Piano Works}

Music is the art of sound, and appreciation is the listening, comprehension, and evaluation of music. Piano works are under a very strong cultural value. Enhancing learners' musical appreciation of piano work is beneficial to increase physical and mental health and effectively improve cultural quality.

\subsection{Enhancing learners' cultural quality and personal accomplishment}

Piano music work can easily reflect cultural values and aesthetic values. Music can combine people's thoughts and souls and allow people to communicate more effectively through music. With the development of piano music teaching, people pay greater attention to the development space of piano culture. Exceptional high-quality teaching can effectively improve learners' artistic accomplishments and musical literacy. They can cultivate learners' rigorous, low-key, and pragmatic learning attitudes. They can even effectively stimulate learners' diligent and self-study learning spirit.

\subsection{Fostering the learner's coordination ability and developing the learner's intelligence}

When learning or appreciating piano music works, learners must be physically and mentally focused. They can increase the learner's sense of music during the learning process, and they can also broaden the learners' thinking ability and memory ability. Depending on the survey, children who began learning piano knowledge in early childhood have strong imagination, acceptance, creativity, and understanding. 


\subsection{Cultivating learners' aesthetic ability and improving the taste of art}

As learners learn piano work, they will be exposed to many piano works and influenced by the piano works' thoughts and emotions. As time passes by, learners will become more cheerful and their emotions will be more abundant. At the same time, they will be in a position to improve learners' music appreciation and music taste.

\section{The Current Status of Piano Music Works}

After all, music appreciation is listening and listening to music. The so-called listening to music here is not simply listening, but in the process of listening, it requires the resonance of spirit and mind to perform the operation of thinking. This requires learners to acquire certain professional knowledge so that they can professionally learn and analyze music. However, having professional music appreciation is no longer a very simple matter. Although some colleges have set up piano music appreciation course and some achievements have been made. However, there are still some problems, such as: the quality of teaching is not ideal. The lack of teachers, teaching facilities is not perfect. Since the reform and opening up, in the process of educational development, the development of music course has not been paid attention to. Under such an imperfect education system, music courses are often replaced by major courses such as mathematics, language, physics, and chemistry. Furthermore, some music teachers have limited knowledge of musical knowledge and musical instrument playing techniques. This very imperfect teaching state can hardly satisfy learners' curiosity. Therefore, schools can often undertake activities to investigate and analyze students' interest in well-being, and actively encourage students who like to study music to develop their specialty. This can greatly increase the students' psychological quality and can also promote the beauty of music to the piano and generates interest in music.

\section{How to Cultivate Piano Works Music Appreciation}

\subsection{Listen to music}

Music is an art form expressed through sounds. This forces us to listen with our ears and listen to the wonderful music. To improve the appreciation of piano music, first, we need to hear a large number of piano works. Music is a very pure time art, so we just have to listen more. If we just listen to a piece of music once, we will not have a deep impression. This requires us to listen repeatedly. Only by constantly listening to music works can we grasp the soul of this piece of work well and bring us a deep inspirational experience, and at the same time, our perception of music will be deeper.

Our purpose is to improve the ability of music appreciation. Obviously it is not enough to just listen to one or a type of music. Therefore, we need to listen to all types of music, expand the scope of music appreciation, and then improve the listening lever of music. We should familiarize ourselves with various types of music, such as Roman music, Renaissance music, classical music, and baroque music.Therefore, repeatedly listening to music works and expanding the level of appreciation can enhance the taste of music.

\subsection{Understand the thought content of piano works}

Music works are social life products produced by composers based on their true emotions. Therefore, in order to improve the appreciation of music, the most important thing is to understand the ideological content of the works, so as to fully appreciate the beauty of the musical works and being familiar with the works theme can deepen the viewer's understanding of the music. For example, Beethoven's "Sixth Symphony" is clearly different from other symphonies in the genre. This symphony is a true emotional description of Beethoven in the country during the period of illness. It depicts a beautiful, quiet, vivid image of the rural natural landscape. Due to the impact of the living environment, so there is a slight change in the creative style of the song. The entire work is delicate, unpretentious, quiet and distant, mainly the memory of rural life. Write more than write 
a scene. It mainly highlights Beethoven's love for nature, as well as his understanding of life.If you do not understand Beethoven and the background of the piece of music well before listening to this piece of music, it is difficult to appreciate the ideological content of the work and the true feelings of the author.

\subsection{Experience the specific emotions of music}

Music is a kind of art that can stimulate emotions. From ancient times to the present, many excellent works have shown the emotional experience of composers in a specific social environment. To enhance the appreciation of musical works, we must thoroughly understand the specific emotions of musical works. Music works express emotions through the contrast of loudness and rhythm. Therefore, when we appreciate music, we must use it to comprehend and carefully listen to the emotional content expressed in this work. For example, when we admired Er Quan Yingyue, this solo erhu from Hua Yanjun started with a painful sigh as if the author had used an insurmountable emotion to us. He described his tough and bumpy life just like an old artist who wanders alone on this bumpy road, but does not succumb to fate. When the slow, shouting melody sounded, that kind of sadness, that bleak feeling came into being. Although for the music appreciator, it is not known what degree of sadness this song represents, but he will never treat the song as a cheerful piece.

\subsection{Combine with other arts}

Music is an independent art, but it also has interdependence and inseparable relations with other arts. There are many similarities between them, and art like painting and poetry also express their emotions through the description of nature and society.The basic expression of art is an element of art. In piano works, the basic elements of the emotion expressed by the author are the changes in the pace of the rhythm and the changes in the strength of the tone. The author can completely change these basic elements to give the piano works a stronger appeal.

Furthermore, when we understand piano works, we can learn from other arts, such as traditional operas, folk paintings, and philosophies. This can help scholars better understand the meaning of piano works and improve the musical appreciation of piano works.

\section{Conclusion}

In summary, cultivating the learner's piano music appreciation ability can effectively improve the learner's aesthetic ability. Music teachers can effectively play musical songs, not only to enable scholars to understand the important material of ancient and modern music knowledge, but also be very effective in improving scholars' appreciation of piano works. When teachers play a representative piece of music, they have a more comprehensive commentary, which can enhance the appreciation of the learner's piano works in a subtle manner, and can also effectively enhance learners' cultural quality and ideological accomplishment. Furthermore, while listening carefully, we must understand the intentions and emotions of the work and also combine it with other arts. This not only enhances the learner's appreciation ability, but also improves the teaching quality and enriches the teaching content.

\section{References}

[1] Sun Caixia. How to Cultivate Students' Appreciation Ability in Music Lessons [J], Academic Weekly, 2016, 13(25):31-32.

[2] Xu Rong. Reflections on Music Appreciation and Improvement of Taste [J], Theater House, 2015, 11(18):54-55.

[3] Li Fengyi. Music Appreciation Teaching Problems and Solutions [J], Teaching and Management, 2011, 10(13):19-20. 